\title{
Effect of diet on infant subcutaneous tissue triglyceride fatty acids
}

James Farquharson, Forrester Cockburn, W Ainslie Patrick, E Cherry Jamieson, Robert W Logan

\begin{abstract}
Having demonstrated a deficiency in infant cerebral cortex docosahexaenoic acid of formula fed compared with breast milk fed infants, we sought to identify why the extensive subcutaneous tissue triglyceride fatty acid reserves in term newborn infants appeared to be ineffectual in its prevention.

In addition to 24 term and six preterm infants who died from 'cot death', tissue was analysed from four perinatal surgical patients and in the former the results were correlated with dietary milk intake. The higher amounts (about $15 \%$ by weight) of unsaturated linoleic acid supplied in the formula milks were quantitatively incorporated into the subcutaneous tissue largely at the expense of the saturated palmitic acid possibly compromising adipocyte fluidity. The six preterm infants were in two formula fed groups and there was only one significant difference, namely a higher subcutaneous tissue concentration of $\alpha$-linolenic acid in one of the preterm groups, distinguishing them from their term counterparts. This may imply that the enzymes involved in absorption and digestion of fatty acids are mature in the preterm infant. From birth the mean weight percentage of docosahexaenoic acid $(0 \cdot 4 \%)$ fell rapidly to undetectable levels $(<0.05 \%)$ in the formula fed group after about two months. It is therefore concluded that if breast feeding is not possible then a minimum daily requirement of
\end{abstract}

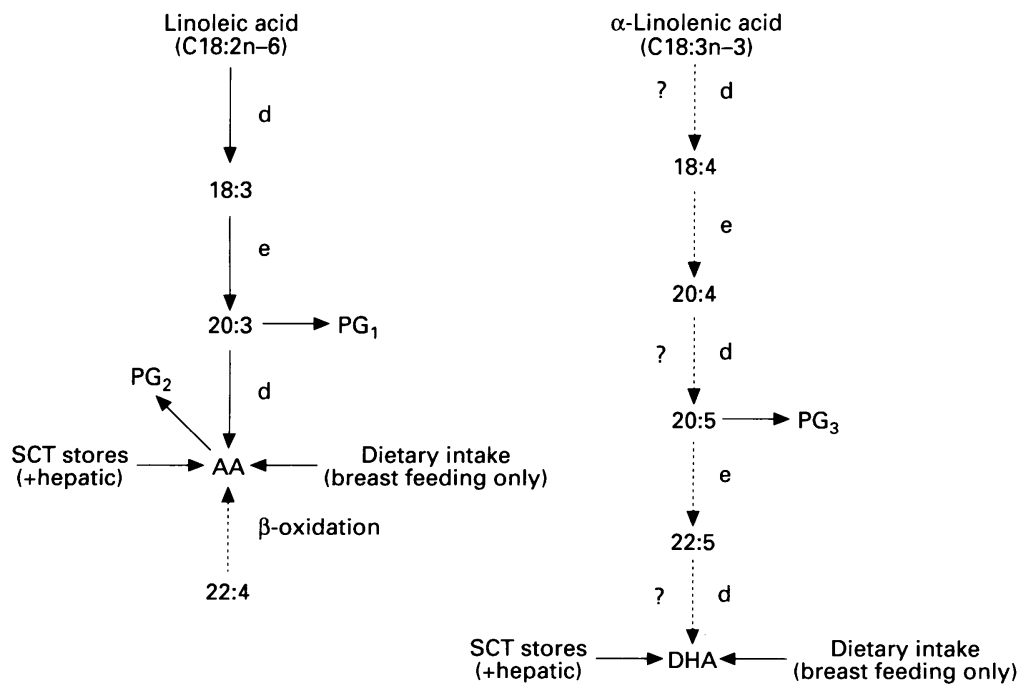

Figure 1 Possible sources of arachidonic $(A A, C 20: 4 n-6)$ and docosahexaenoic acid (DHA, C22:6n-3) in the term infant. SCT $=$ subcutaneous tissue; $e=$ elongase and $d=$ desaturase activity; ?= enzyme activity; $P G_{\mathrm{n}}=$ series $n$ prostaglandins.
$30 \mathrm{mg}$ docosahexaenoic acid $(\approx 0 \cdot 2 \mathrm{~g} / 100 \mathrm{~g}$ fatty acids) should be supplied in formulas designed for term infants to prevent the cerebral cortical deficiency of docosahexaenoic acid.

(Arch Dis Child 1993; 69: 589-593)

At birth in the term newborn human infant by far the most extensive reserves of fatty acids are those of the adipose tissues. It is known that human dietary and adipose tissue fatty acids are closely related. However, most of the data are restricted to either animal models ${ }^{1}$ in which the essential fatty acids, linoleic (C18:2n-6) and $\alpha$-linolenic (C18:3n-3), would normally be supplied by plant life directly to herbivores and thence indirectly to the carnivores, or to adult humans ${ }^{2}$ in whom both routes of supply are available to non-vegans.

In addition there is a dearth of information about the metabolism of infant adipocyte fatty acids and whether in early life they play a crucial part in the supply to the growing and developing tissues or merely act as a depot for fats that are excess to requirement. Milk feeds vary greatly in their composition of both the essential fatty acids and their $n-6$ and n- 3 series long chain polyunsaturated fatty acid (PUFA) derivatives. If the infant's postnatal diet does influence PUFA storage levels and there are deficiencies in dietary PUFA, then with rapid turnover depletion of adipocyte fatty acid stores may become evident. Alternatively a reduction in essential fatty acid mobilisation to neural tissue might be caused by neonatal enzyme immaturity especially in the preterm infant. Also some uncertainty exists as to the exact nature of the subcutaneous tissue triglyceride fatty acid composition because of the concurrent isolation of the adipocyte membrane phospholipid fatty acids. ${ }^{3}$

As evolution has determined that arachidonic acid (C20:4n-6) and docosahexaenoic acid (C22:6n-3), are supplied directly to the infant through breast feeding we may hypothesise that this may have obviated the need for the essential fatty acid desaturase enzymes to be fully active in early life, predisposing formula milk fed infants to PUFA deficiency.

Having established the effect of infant diet on subsequent cerebral cortex phospholipid fatty acid composition, ${ }^{4}$ the authors sought to identify whether depletion of subcutaneous tissue stores could have been a contributory factor to the deficiency of docosahexaenoic acid in the structural lipids of the cerebral cortex found in formula fed infants (fig 1). We therefore present here the analysis of 
Infant characteristics and subcutaneous tissue triglyceride fatty acid composition and diet

\begin{tabular}{|c|c|c|c|c|}
\hline & \multicolumn{4}{|l|}{ Diet } \\
\hline & $\begin{array}{l}\text { Breast } \\
\text { milk }\end{array}$ & $S M A$ & CGOST & $\begin{array}{l}\text { Perinatal } \\
\text { biopsy } \\
\text { group }\end{array}$ \\
\hline $\begin{array}{l}\text { Mean age (weeks) } \\
\text { Range } \\
\text { Male/female } \\
\text { Fatty acid` }\end{array}$ & $\begin{array}{l}10 \cdot 6 \\
5-21 \\
2 / 5\end{array}$ & $\begin{array}{l}17 \cdot 0 \\
6-22 \\
8 / 1\end{array}$ & $\begin{array}{c}17 \cdot 5 \\
9-29 \\
5 / 1\end{array}$ & $\begin{array}{l}0 \cdot 4 \\
0 \cdot 1-0 \cdot 8 \\
3 / 1\end{array}$ \\
\hline Lauric & $2 \cdot 3$ & $5 \cdot 1 \ddagger$ & $3 \cdot 7 \ddagger$ & $0.2(0.05)$ \\
\hline (C12:0) & $\begin{array}{l}(1 \cdot 4-2 \cdot 6) \\
6 \cdot 1 \\
(4 \cdot 9-7 \cdot 6)\end{array}$ & $\begin{array}{l}(3 \cdot 7-6 \cdot 3) \\
6 \cdot 0 \\
(5 \cdot 4-6.5)\end{array}$ & $\begin{array}{l}(2 \cdot 8-4 \cdot 2) \\
5 \cdot 1 \\
(4 \cdot 3-5 \cdot 4)\end{array}$ & $3.5(0.32)$ \\
\hline $\begin{array}{l}\text { (C14:0) } \\
\text { Myristoleic } \\
(\text { C14:1n-5) }\end{array}$ & $\begin{array}{l}(4 \cdot 9-7 \cdot 6) \\
0 \cdot 5 \\
(0 \cdot 4-0 \cdot 8)\end{array}$ & $\begin{array}{l}(5 \cdot 4-6 \cdot 5) \\
0.5 \\
(0.4-0.8)\end{array}$ & $\begin{array}{l}(4 \cdot 3-5 \cdot 4) \\
0 \cdot 5 \\
(0 \cdot 3-0 \cdot 6)\end{array}$ & $0.4(0.08)$ \\
\hline $\begin{array}{l}\text { Palmitic } \\
\text { (C16:0) }\end{array}$ & $\begin{array}{l}30 \cdot 4 \\
(26 \cdot 1-37 \cdot 8)\end{array}$ & $\begin{array}{l}21 \cdot 30 \\
(19 \cdot 4-30 \cdot 3)\end{array}$ & $\begin{array}{l}23.0 \ddagger \\
(21.9-25 \cdot 5)\end{array}$ & $46.2(1.97)$ \\
\hline $\begin{array}{l}\text { Palmitoleic } \\
\text { (C16:1n-7) }\end{array}$ & $\begin{array}{l}7 \cdot 6 \\
(5 \cdot 6-9 \cdot 7)\end{array}$ & $\begin{array}{l}4 \cdot 7 \| \\
(3 \cdot 2-9 \cdot 4)\end{array}$ & $\begin{array}{l}5.0 \ddagger \\
(3 \cdot 3-5 \cdot 5)\end{array}$ & $13.6(1.05)$ \\
\hline $\begin{array}{l}\text { Stearic } \\
\text { (C18:0) }\end{array}$ & $\begin{array}{l}5 \cdot 0 \\
(3 \cdot 4-5 \cdot 9)\end{array}$ & $\begin{array}{l}4 \cdot 5 \\
(3 \cdot 3-5 \cdot 1)\end{array}$ & $\begin{array}{l}3 \cdot 1 \dagger \\
(2 \cdot 0-3 \cdot 8)\end{array}$ & $4 \cdot 0(0 \cdot 10)$ \\
\hline $\begin{array}{l}\text { Oleic } \\
\text { (C18: } \ln -9)\end{array}$ & $\begin{array}{l}38 \cdot 1 \\
(34 \cdot 9-45 \cdot 1)\end{array}$ & $\begin{array}{l}41 \cdot 3 \\
(36.0-43.9)\end{array}$ & $\begin{array}{l}45 \cdot 3 \dagger \\
(42 \cdot 5-48 \cdot 1)\end{array}$ & $28.9(1.80)$ \\
\hline $\begin{array}{l}\text { Eicosenoic } \\
(\text { C20:1n-9) }\end{array}$ & $\begin{array}{l}0.6 \\
(0.5-0.8)\end{array}$ & $\begin{array}{l}0.4 \ddagger \\
(0.3-0.6)\end{array}$ & $\begin{array}{l}0.5 \\
(0.4-0.9)\end{array}$ & ND \\
\hline $\begin{array}{l}\text { Linoleic } \\
\text { (C18:2n-6) }\end{array}$ & $\begin{array}{l}6 \cdot 6 \\
(3 \cdot 6-11 \cdot 1)\end{array}$ & $\begin{array}{l}13 \cdot 6 \ddagger \\
(9 \cdot 3-15 \cdot 2)\end{array}$ & $\begin{array}{l}13 \cdot 8 \ddagger \\
(9 \cdot 8-16 \cdot 2)\end{array}$ & $2 \cdot 2(0.62)$ \\
\hline $\begin{array}{c}\alpha-\text { Linolenic } \\
(\mathrm{C} 18: 3 n-3)\end{array}$ & $\begin{array}{l}0.4 \\
(0.3-0.9)\end{array}$ & $\begin{array}{l}1 \cdot 0 \ddagger \\
(0 \cdot 8-1 \cdot 2)\end{array}$ & $\begin{array}{l}0 \cdot 2 \ddagger \\
(0 \cdot 1-0 \cdot 3)\end{array}$ & $0.1(0.01)$ \\
\hline $\begin{array}{l}\text { Arachidonic } \\
\text { (C20:4n-6) }\end{array}$ & $\begin{array}{l}0.3 \\
(0.1-0.5)\end{array}$ & $\begin{array}{l}0.15 \\
(0.1-0.3)\end{array}$ & $\begin{array}{l}0 \cdot 1 \| \\
(0 \cdot 1-0.2)\end{array}$ & $0.7(0.12)$ \\
\hline $\begin{array}{l}\text { Docosahexaenoic } \\
(\mathrm{C} 22: 6 n-3)\end{array}$ & $\begin{array}{c}0 \cdot 1 \\
(\mathrm{ND}-0 \cdot 3)\end{array}$ & $\begin{array}{l}\text { ND } \ddagger \\
(\mathrm{ND}-0 \cdot 1)\end{array}$ & $\begin{array}{l}\text { NDł } \\
\text { (ND) }\end{array}$ & $0.4(0.04)$ \\
\hline
\end{tabular}

*Weight percentage of total fatty acids present expressed as median (range) except perinatal biopsy group results expressed as mean (SD). $t \mathrm{p}<0.05, \neq \mathrm{p}<0.002, \mathrm{p}<0.01, \| \mathrm{p}<0.02$, all calcu biopsy group results expressed as mean (SD). $t p<0.05, \neq p<0.002, \oint p<0.01, \| p<0.02$, all calc
lated by the two tailed, non-parametric Mann-Whitney U test. ND $=$ not detected or $<0.05 \%$.

subcutaneous tissue fatty acids from infants who died from 'cot death' and newborn infants presenting for surgery and in the former relate these to the milk fat ingested.

\section{Subjects and methods}

The subjects, resident in the Greater Glasgow Health Board area, were cot death victims all of whom died within 30 weeks of birth and whose medical and dietary histories were recorded either from parental interview or examination of police and medical records. Subcutaneous tissue was obtained at necropsy from the abdominal or chest wall of 24 term infants (gestational age range 37-42 weeks) and six preterm, born between 30 and 33 weeks' gestation. Eight of the infants had been breast fed, 10 were fed SMA (Wyeth), and six either Cow and Gate 'Premium' or Farley's 'Ostermilk'. The Cow and Gate and Farley groups were combined and designated CGOST as at the time of the survey (May 1987-September 1989) their fatty acid compositions were similar with the content of $\alpha$-linolenic acid $(0.4 \%)$ being significantly lower than that of SMA $(1 \cdot 5 \%)$. During this period the other essential fatty acid, linoleic, was present at between 12 and $16 \%$ of total fatty acids in all three formulas. Breast milk alone, however, contained the main PUFAs derived from these parent essential fatty acids, namely arachidonic acid and docosahexaenoic acid. The milk ingested was exclusive to the group, however five infants (one breast fed and two each from the SMA and CGOST groups) received some solids in their diet. Of the six preterm infants, three were fed the CGOST regimen and three SMA with one of the latter also taking solids.
In addition abdominal or chest wall subcutaneous fat was obtained from four term surgical patients (gestational age range 38-41 weeks) receiving either minimal or no prior dietary intake and subsequently designated as a perinatal biopsy group. The subjects ranging from 1 to 6 days old were operated on for an imperforate anus, tracheo-oesophageal fistula (two cases), and right hydronephrosis. We considered that results from this group would enable us to establish the bioavailability of stored arachidonic acid, docosahexaenoic acid, and their essential fatty acid precursors at birth.

After storage at $-60^{\circ} \mathrm{C}$ each tissue (about $50 \mathrm{mg}$ ) was added to chloroform $(4 \mathrm{ml})$, hand homogenised to solubilise the triglycerides, and the remaining adipocyte membrane discarded. The absence of structural membrane phopholipids in extracts was verified by silica gel thin layer chromatography. Apart from the addition of $1 \mathrm{ml}$ of chloroform to the derivatisation reagent $(2 \mathrm{ml})$ and extension of the gas chromatography temperature programming from 130 to $200^{\circ} \mathrm{C}$ to elute the shorter chain length $\mathrm{C} 12$ and $\mathrm{C} 14$ fatty acids, the method was as previously described. ${ }^{4}$

Statistical analyses of the differences both between the three feeding groups and between the term and preterm infants within the SMA and CGOST groups were performed by the two tailed, non-parametric Mann-Whitney U test. This method was deemed to be the most appropriate as results distributions especially in the breast fed group tended to be skewed. Results from infants younger than 1 month were omitted, leading to the exclusion of one breast fed and one SMA fed infant, both 2 weeks old.

\section{Results}

Triglyceride fatty acid content of the subcutaneous tissue was calculated for the eight most abundant non-essential fatty acids. In addition because of their importance the essential fatty acids linoleic and $\alpha$-linolenic together with their derivatives arachidonic acid and docosahexaenoic acid expressed as weight percentage of total fatty acid methyl esters are shown, and significant differences between the breast fed and formula fed groups are given (table). No statistical analysis was performed between the perinatal biopsy results, displayed as means and SDs and those of the feeding groups. Although there were significant differences in the non-essential fatty acids between the breast fed and both formula fed groups the most prominent differences were found in lauric (C12:0), palmitic (C16:0), and palmitoleic acids (C16:1n-7). In each group concentrations tended to be in proportion to their dietary intake. The essential fatty acids linoleic and $\alpha$-linolenic were both significantly different in the subcutaneous fats of the formula fed SMA and CGOST groups from the breast fed group (table) and their age related distributions can be seen in figs 2 and 3 respectively. While the $\alpha$-linolenic acid concentration of the SMA fed infants was significantly higher $(p<0.002)$ 

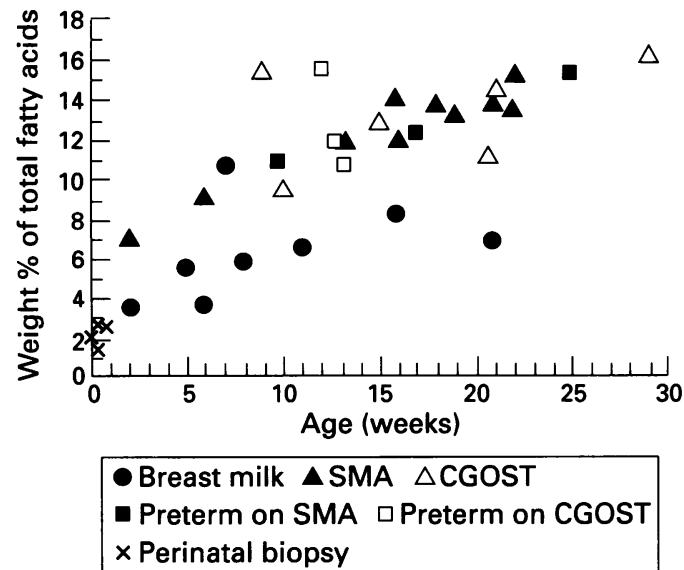

Figure 2 Subcutaneous tissue triglyceride linoleic acid (C18:2n-6) in relation to infants' diet and age.

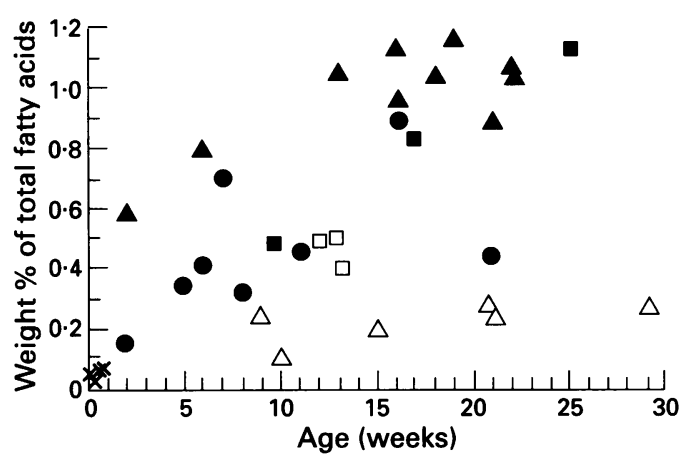

- Breast milk $\triangle$ SMA $\triangle$ CGOST

- Preterm on SMA 口Preterm on CGOST $\times$ Perinatal biopsy

Figure 3 Subcutaneous tissue triglyceride $\alpha$-linolenic acid $(C 18: 3 n-3)$ in relation to infants' diet and age.

than that of those breast fed, in contrast the CGOST group concentration was lower $(p<0.002)$. Both formula groups also had arachidonic acid and docosahexaenoic acid concentrations significantly lower than the breast fed group, albeit at levels in the case of docosahexaenoic acid that were undetectable $(<0.05 \%$; table). The distribution of results of these PUFAs is given in figs 4 and 5 with the docosahexaenoic acid limit of detection represented in fig 5 by the broken line. The $\alpha$-linolenic acid content was greater $(p<0.002)$ in the SMA fed infants than those fed CGOST. Analysis of the four perinatal biopsy tissues showed that at birth amounts of triglyceride fatty acids in the subcutaneous tissue cover a narrow range (table). Subsequently palmitic and palmitoleic acids which initially accounted for about $60 \%$ of total fatty acids were replaced primarily by oleic (C18:1n-9) and linoleic acid, the latter postnatally being derived solely from dietary intake. In the first week of life very low reserves of $\alpha$-linolenic $(0.1 \%)$ were present in the subcutaneous tissue, although these increased rapidly to levels strongly reflecting dietary provision (fig 6). In the case of the long chain PUFA both arachidonic acid $(0.7 \%)$ and docosahexaenoic acid $(0.4 \%)$ were detected in significant amounts at birth but these fell rapidly postnatally in all feeding groups.

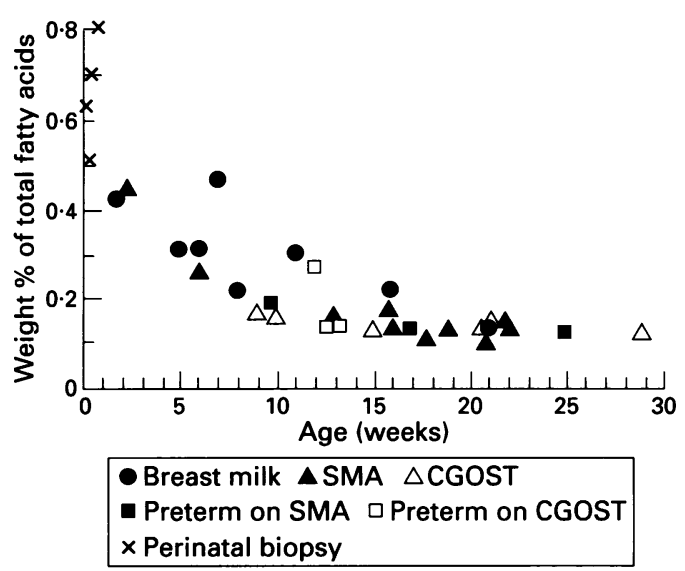

Figure 4 Subcutaneous tissue triglyceride arachidonic acid (C20:4n-6) in relation to infants' diet and age.

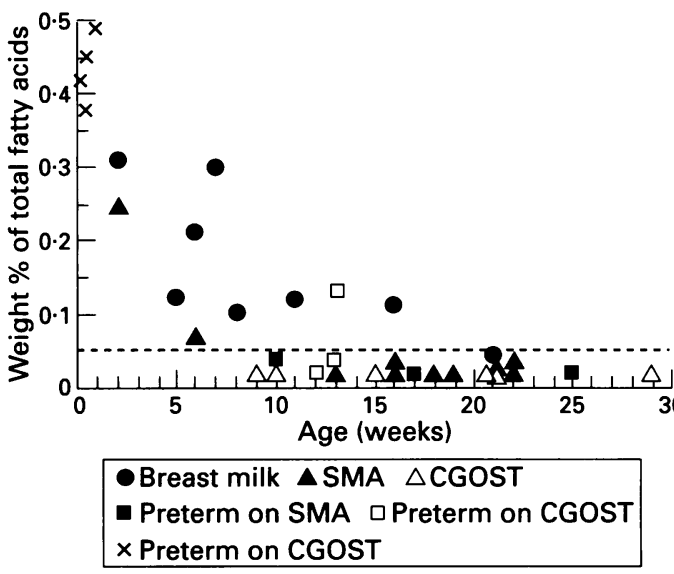

Figure 5 Subcutaneous tissue triglyceride docosahexaenoic acid (C22:6n-3) in relation to infants' diet and age.

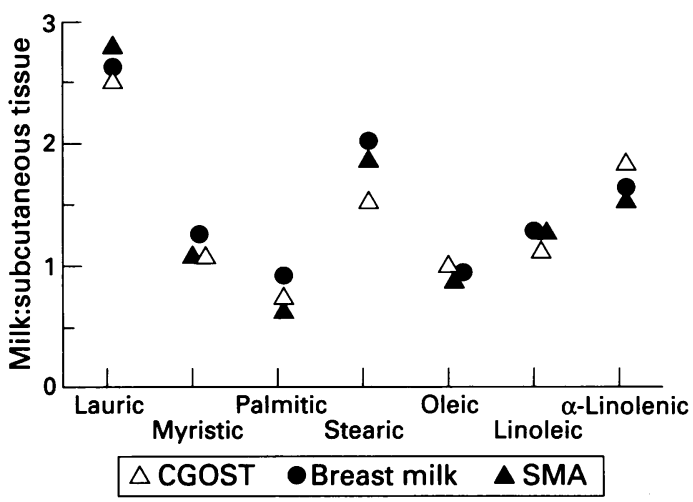

Figure 6 Milk:subcutaneous tissue ratios (weight \%) of the major fatty acids in relation to infants' diet.

Although there were only three specimens in each group, analysis of the results from the preterm SMA and CGOST fed infants yielded only one significant difference $(p<0.05)$ from their term counterparts, namely a higher mean concentration of $\alpha$-linolenic $(0.46 \%)$ in the preterm CGOST fed group (fig 3), although no correction was made for gestational age.

\section{Discussion}

It is apparent from the results that physiological equilibrium for each fatty acid is not reached until about 4 weeks of age by which time relative rates of deposition and mobilisation appear to remain constant. In the 
newborn subcutaneous tissue changes in the non-essential fatty acids lead rapidly to a composition similar to that found in adults, ${ }^{56}$ and as replacement of palmitic acid is largely achieved by insertion of the unsaturated fatty acids oleic and linoleic, the resultant increase in fluidity may aid the hormone induced mobilisation of fatty acids for energy supply. In the formula fed infants an increased incorporation ( $13 \%$ by weight) of linoleic acid (fig 2) appears to further suppress deposition of palmitic acid in the adipocytes when compared with breast fed infants. This dietary modification of subcutaneous tissue fatty acid composition may, however, also be evident in the essential fatty acids of the 7 and 16 week old breast fed infants in whom disproportionately high levels of both linoleic and $\alpha$-linolenic acid were found (figs 2 and 3) and may be indicative of maternal vegetarian diets. As such diets are increasingly being regarded as 'healthy' it is worthwhile noting that especially in the USA formulas with extremely high levels of both these essential fatty acids are marketed, ${ }^{7}$ although research has shown that such nonphysiological amounts are readily incorporated into the subcutaneous tissue in the approximate weight percentages at which they are supplied. ${ }^{8}$ We believe that if concentrations of the essential fatty acids found in breast milk are optimal then the amounts provided in such formulas must be largely excess to requirement and as previously discussed $\alpha$-linolenic acid will be ineffective in the synthesis of docosahexaenoic acid in the preterm infant in whom the appropriate enzyme systems are immature. ${ }^{4}$ Furthermore, at the onset of enzyme maturity it is probable that the high concentrations of linoleic acid will inhibit $\alpha$-linolenic acid metabolism and vice versa. It is unfortunate that the important role of the essential fatty acids in formulas as precursors of the structural long chain PUFAs crucially involved in neurodevelopment and maintenance of membrane and vascular integrity has been ignored or neglected. These PUFAs also uniquely act as the initial substrates in multistage syntheses that ultimately yield the prostaglandin, leukotriene, and thromboxane families of bioactive molecules.

It has been our experience in the study of medium chain acyl-CoA dehydrogenase deficiency in infants that this metabolic defect in the $\beta$-oxidation of fatty acids, which leads to the initial accumulation of medium chain acylcarnitines, acylglycines, and dicarboxylic acids in the tissues can remain undiagnosed for several months until precipitated by a crisis such as infection or fasting it induces hypoglycaemic coma. ${ }^{9}$ It appears that in the term infant the main source of energy can be provided by the carbohydrate intake and until this and the hepatic glycogen stores are exhausted a secondary role in such provision is undertaken by fatty acid oxidation. The consideration of essential fatty acids in respect of their energy value culminated in $\alpha$-linolenic acid being virtually regarded as superfluous to requirement in the developing infant, resulting in its presence in only 'trace' amounts in some formulas despite its position as parent molecule to all n-3 series long chain PUFAs.

During the period of this study low concentrations of $\alpha$-linolenic acid were still prevalent in some formulas and are reflected in the concentrations found in the adipose tissue (fig 3). From examination of the perinatal biopsy specimens it is evident that at birth in the term infant reserves of arachidonic acid and docosahexaenoic acid are present as a result of preferential placental supply and fetal uptake. The stores, however, cannot readily be replenished by infants receiving formula milk devoid of these fats and accordingly their levels fall rapidly in the first few weeks of life (figs 4 and 5). Although breast fed infants are ingesting both arachidonic acid and docosahexaenoic acid they too experience reductions during the same period, but these are less pronounced, with docosahexaenoic acid undetected $(<0.05 \%)$ only in the oldest infant at 21 weeks. This may, by reflecting the falling docosahexaenoic acid concentration in breast milk, be indicative of the approximate age at which weaning of the infant could be considered without prejudice to the long chain PUFA status. ${ }^{10}$

It is interesting to observe that the preterm SMA and CGOST fed infants had subcutaneous tissue fatty acid compositions practically indistinguishable from their term contemporaries. This would tend to imply that the enzyme systems involved in the digestion and absorption of dietary fatty acids, namely the lingual, gastric, duodenal, and lipoprotein lipases may be mature, although it should be recognised that adipose tissue in these infants at birth is only about one tenth by weight of that in term infants. ${ }^{11}$ The one exception to this finding in premature infants is the higher level of $\alpha$-linolenic acid found in the subcutaneous tissue of the CGOST fed group (fig 3) and may represent an imbalance in the equilibrium between fatty acid deposition and mobilisation due to a reduction in the latter caused by n-3 series desaturase enzyme immaturity compounded by a high linoleic: $\alpha$-linolenic acid ratio in the milk feed.

In the developing infant cerebrum about $6 \mathrm{~g}$ of docosahexaenoic acid are required solely for the formation of cerebral cortex phospholipid in the first year (assuming an annual 50\% turnover of neural docosahexaenoic acid substrate). From our results at birth in the term infant with an average $350 \mathrm{~g}$ subcutaneous tissue fat about $1 \mathrm{~g}$ of docosahexaenoic acid is present and this is quickly exhausted especially in those fed formula milks. It is apparent, however, that this docosahexaenoic acid is not specifically directed towards the formation of neuronal membranes otherwise no deficit in cerebral cortex phospholipid docosahexaenoic acid would be detected at least in the first few months of life. A similar outcome is encountered on analysis of the term SMA and CGOST fed groups between which lies the main statistical difference in the level of stored subcutaneous tissue $\alpha$-linolenic acid that at about $3 \mathrm{~g}$ is five times greater in the SMA group and if quantitatively converted and incorporated preferentially into neural membranes would again be more than adequate to fulfil 
requirements for cerebral cortex phospholipid docosahexaenoic acid in early life. However, despite generally higher levels in such phospholipids of the SMA group than the CGOST, the differences did not reach statistical significance, ${ }^{4}$ with the resultant conclusion that subcutaneous tissue $\alpha$-linolenic acid' as with docosahexaenoic acid may be predominantly utilised in non-neurological membrane development or undergo mitochondrial oxidation. Assuming normal fetal cerebral growth we are therefore led to the inevitable conclusion that the cortex phospholipid . docosahexaenoic acid deficit in the SMA and CGOST fed infants of about $0.9 \mathrm{~g}(30 \%)$ and $1.1 \mathrm{~g}(35 \%)$ respectively at 16 weeks must necessarily be due to dietary insufficiency and be rectified accordingly.

With a daily formula milk intake of $600 \mathrm{ml}$ (about $150 \mathrm{ml} / \mathrm{kg}$ ) this should include a theoretical absolute minimum amount of $10 \mathrm{mg}$ docosahexaenoic acid but allowing for fat digestion, absorption, and subsequent metabolic processing a more realistic minimum of $30 \mathrm{mg}$ docosahexaenoic acid/day or $0.2 \mathrm{~g} / 100 \mathrm{~g}$ total fatty acids with present artificial milk formulations may be more appropriate. Finally, as evolution has produced a situation in which accretion of cerebral fatty acids from human milk in the first months of life dominates human infant development, ${ }^{12}$ then interference in this process must be considered at best unwise.
The authors would like to acknowledge Dr Angus Gibson, pathology department, and our surgical colleagues for the provision of specimens. We are also indebted to Mrs Myra Fergusson and Miss Jean Hyslop for preparation of this manuscript.

1 Lin DS, Connor WE. Are the n-3 fatty acids from dietary fish oil deposited in the triglyceride stores of adipose fish oil deposited in the triglyceride stor
tissue? Am $\mathcal{F}$ Clin Nutr 1990; 51: 535-9.

2 Walldius G. Serum triglycerides and fatty acid incorporation into human adipose tissue (FIAT). Acta Medica Scandiavica 1976; 200: 409-21.

3 Clandinin MT, Chappell JE, Heim T, Swyer PR, Chance $\mathrm{GW}$. Fatty acid utilisation in perinatal de novo synthesis of tissues. Early Hum Dev 1981; 5: 355-66.

4 Farquharson J, Cockburn F, Patrick WA, Jamieson EC, Logan RW. Infant cerebral cortex phospholipid fatty acid composition and diet. Lancet 1992; 340: 810-3.

5 Malcom GT, Bhattacharyya AK, Velez-Duran M, Guzman MA, Oalmann MC, Strong JP. Fatty acid composition of adipose tissue in humans: differences between subcutaadipose tissue in humans: differences between

6 Cassidy DM, Pratt DA, Taylor R, Alberti KG, Laker MF. Capillary column gas chomatography-mass spectrometry for the determination of the fatty acid composition of human adipose tissue. F Chromatogr 1989; 491: $1-13$.

7 Jensen RG, Hagerty MH, McMahon KE. Lipids of human milk and infant formulas: a review. Am $\mathcal{F}$ Clin Nutr 1973; 31: $990-1016$

8 Widdowson EM, Dauncey MJ, Gairdner DMT, Jonxis JHP, Pelikan-Filipkova M. Body fat of British and Dutch infants. $B M \mathcal{F}$ 1975; i: 653-5.

9 Farquharson J, Jamieson EC, Muir J, Cockburn F, Logan RW. Direct gas chromatographic assay of urinary medium-chain fatty acylcarnitines by their thermal medium-chain fatty acylcarnitines by their the

10 Harzer G, Haug M, Dieterick I, Gentner PR. Changing patterns of human milk lipids in the course of thelactation and during the day. Am F Clin Nutr 1983; 37: $612-21$.

11 Clandinin MT, Chappell JE, Van Aerde JEE. Requirements of newborn infants for long chain polyunsaturated fatty acids. Acta Pediatr Scand 1989; 351 (suppl): 63-71.

12 Crawford MA, Harbige LS. n-3 fatty acids and the evolution of the brain. Prog Clin Biol Res 1988; 282: 335-54. 